\title{
Informação e conhecimento acessíveis aos deficientes visuais nas bibliotecas universitárias
}

Janaina Fialho

\begin{abstract}
Professora Adjunta do Curso de Biblioteconomia da Universidade Federal de Goiás. Doutora em Ciência da Informação
\end{abstract}

Daiane de Oliveira Silva

\begin{abstract}
Bibliotecária graduada pela Universidade Federal de Goiás.
\end{abstract}

As bibliotecas universitárias precisam ser acessíveis, para que possam atender às necessidades informacionais diversas do público que as procura, tais como os deficientes visuais. Elas fazem parte do processo de desenvolvimento acadêmico do estudante com deficiência visual, cumprindo sua função primordial de apoiarem as pesquisas e promoverem o acesso à informação. Para que isso ocorra, deve haver uma preocupação, por parte das universidades, com a adaptação e estrutura voltada para atender esse tipo de usuário. O bibliotecário é responsável por intermediar o acesso à informação, permitindo que os deficientes visuais possam usufruir desse acesso. Com base na experiência da Biblioteca Braille José Álvarez de Azevedo em Goiânia e na literatura sobre o assunto, foram feitas algumas sugestões de equipamentos e softwares direcionados para os deficientes visuais em bibliotecas universitárias. Concluise que softwares e equipamentos são instrumentos importantes para o deficiente visual ter acesso à informação, bem como o preparo dos profissionais para atendê-lo. Com bons recursos disponíveis gratuitamente no mercado, as bibliotecas universitárias podem equipar seus espaços de apoio ao deficiente visual, inclusive o acesso à Internet.

Palavras-chave: Biblioteca universitária; Acessibilidade; Deficiente visual; Acesso à informação; Biblioteca Braille José Álvarez de Azevedo. 


\section{Information and knowledge accessible to the visually impaired at university libraries}

University libraries need to be accessible in order to answer the public's demand for different kinds of information and that includes the visually impaired. Libraries are part of the academic development of the students with visual impairments, fulfilling their elementary functions which are to support research and promote access to information. For this to occur there must be a concern on the part of universities to adapt and build a structure designed to meet this type of users needs. The librarian is responsible for mediating access to information as well as allowing the visually impaired to take advantage of such access. Based on the experience of José Alvarez de Azevedo Braille Library, located in Goiania, and in the subject-specific literature, it was made some suggestions for university libraries' equipment and software which target the visually impaired public. We concluded that software and equipment are important tools to enable the visually impaired to access information. It is also important to prepare the professionals who will help them in doing so. Considering all good resources freely available on the market, university libraries can set up their spaces of support to the visually impaired, especially with regard to Internet access.

Keywords: University library; Accessibility; Visually impaired; Access to information; José Álvarez de Azevedo Braille Library.

Recebido em 04.05.2011 Aceito em 25.01.2012

\section{Introdução}

Atualmente existe a preocupação de diversas instituições em oferecer serviços e produtos acessíveis a todas as pessoas. Como não poderia deixar de ser, as bibliotecas e unidades de informação têm procurado se inserir no universo da acessibilidade. A proposta deste trabalho é demonstrar que as bibliotecas universitárias podem implementar projetos de acessibilidade a deficientes visuais, de baixo custo e rápida implementação. Enfatiza-se o papel do responsável pela 
unidade de informação em adaptar e tornar suas bibliotecas acessíveis para atender essa demanda especial de usuários.

Para uma biblioteca ser acessível, é necessário que acolha um maior número de pessoas em suas atividades, que tenha instalações adequadas para atender cada um, conforme suas diferenças físicas, antropométricas e sensoriais; somando-se a isso a acessibilidade digital e tecnológica de forma organizada. Além disso, os funcionários devem ser solícitos no momento do atendimento, permitindo a acessibilidade. A parte arquitetônica e os produtos são fundamentais para um planejamento de biblioteca que seja acessível.

Entende-se por biblioteca universitária acessível a deficientes visuais aquela que oferece condições de apoiar o acesso à informação em diversos suportes, permitindo que os usuários com deficiência visual sejam incluídos na sociedade. Na instituição de ensino superior, esses usuários contam com aparatos nas etapas de preparo para sua formação, como, por exemplo, a Secretaria de Educação Superior, que, com apoio da Secretaria de Educação Especial, estabelece requisitos de acessibilidade, tomando-se como referência a NBR 9050 (ASSOCIAÇÃO BRASILEIRA DE NORMAS TÉCNICAS - ABNT, 2004). No que concerne aos estudantes com deficiência visual, o compromisso da instituição de ensino deve se estender do início à conclusão do curso superior, a qual deve manter sala preparada com diversos tipos de equipamentos, bem como acervo bibliográfico em Braille e de fitas sonoras.

Para garantir a satisfação desses usuários e para que se tornem mais independentes no momento em que procuram os serviços oferecidos pelas bibliotecas universitárias, é necessário, primeiramente, um bom atendimento oferecido pelos funcionários da biblioteca e a disposição de equipamentos apropriados para permitir o acesso à informação. Dessa forma, serão eliminadas as barreiras que impedem a acessibilidade e os usuários não se sentirão discriminados. Com o intuito de contribuir com a adaptação e acessibilidade para deficientes visuais em bibliotecas universitárias, são oferecidas, neste trabalho, algumas sugestões de equipamentos e softwares para deficientes visuais em bibliotecas universitárias, elementos fundamentais para que as mesmas possam suprir a demanda com um serviço de qualidade.

\section{Revisão de literatura}

A acessibilidade na biblioteca universitária é fundamental para que todos os usuários se sintam incluídos na sociedade, devendo haver uma preocupação, por parte dos profissionais da informação, em adequar suas unidades de informação para atender toda uma diversidade de usuários. Inclui-se, desse modo, usuários com deficiências visuais, cumprindo seu papel que é o de apoiar o estudante do início ao final do curso. 


\subsection{Acessibilidade de pessoas com deficiência em bibliotecas universitárias}

As bibliotecas universitárias têm como um de seus objetivos possibilitarem acessibilidade à informação; quando esse acesso é direcionado aos usuários com necessidades especiais, surgem diversas barreiras. Existem garantias para que as pessoas com deficiência possam ter acesso à informação, mas, infelizmente, nem sempre são concretizadas. Em uma biblioteca, a acessibilidade é fundamental, devendo a mesma estar preparada para atender a demanda, sendo os usuários com necessidades especiais ou não.

Existem, atualmente, diferentes entendimentos do que venha a ser acessibilidade. Segundo Pupo, Melo e Ferrés (2006), a primeira perspectiva é relacioná-la à melhoria da qualidade de vida de idosos e pessoas com algum tipo de limitação. Entretanto, em um sentido mais amplo, "acessibilidade ou possibilidade de alcance aos espaços físicos, à informação, aos instrumentos de trabalho e estudo, aos produtos e serviços diz respeito à qualidade de vida de todas as pessoas" (PUPO; MELO; FERRÉS, 2006, p. 17). Verificam-se, dessa forma, alguns quesitos básicos, que, aliados à tecnologia, constituem uma sociedade acessível (PUPO; MELO; FERRÉS, 2006, p. 18):

a) acessibilidade arquitetônica: não deve haver barreiras ambientais físicas nas casas, nos edifícios, nos espaços ou equipamentos urbanos e nos meios de transportes individuais ou coletivos;

b) acessibilidade comunicacional: não deve haver barreiras na comunicação interpessoal, escrita e virtual;

c) acessibilidade metodológica: não deve haver barreiras nos métodos e técnicas de estudo, de trabalho, de ação comunitária e de educação dos filhos;

d) acessibilidade instrumental: não deve haver barreiras nos instrumentos, utensílios e ferramentas de estudo, de trabalho, e de lazer ou recreação;

e) acessibilidade programática: não deve haver barreiras invisíveis embutidas em políticas públicas e normas ou regulamentos; e

f) acessibilidade atitudinal: não deve haver preconceitos, estigmas, estereótipos e discriminações.

De acordo com Paula e Carvalho (2009), é garantida à pessoa com deficiência, de acordo com a Portaria no. 3.284, do Ministério de Educação e do Desporto (MEC) (BRASIL, 2003), o acesso à educação em todos os níveis, tanto em instituições públicas como privadas, e as necessidades do estudante devem ser garantidas até o final do curso. As bibliotecas devem 
ser acessíveis, possibilitando que quem as procuram, consiga satisfazer suas necessidades de busca de informação. Como citado por Mazzoni et al. (2001), assim como os locais de trabalho, instituições educacionais precisam ser acessíveis, observando os princípios da acessibilidade. Segundo Pupo, Melo e Ferrés (2006), existem alguns documentos que tratam da deficiência em plano internacional, tais como:

a) Declaração de Direitos Humanos da ONU, em 1948;

b) Carta para o Terceiro Milênio - Reabilitação Internacional, em 09/09/1999 - propõe medidas para proteger os direitos das pessoas com deficiência mediante o apoio ao pleno empoderamento (empowerment) e inclusão em todos os aspectos da vida;

c) Declaração de Madri, em 21/05/2002 - estabelece parâmetro conceitual para a construção de uma sociedade inclusiva, focalizando os direitos das pessoas com deficiência, as medidas legais, a mudança de atitude e a vida independente, dentre outros; e

d) Declaração de Quito, de 11/04/2003 - na qual os governos da América Latina defendem uma Convenção Internacional para Proteção e Promoção dos Direitos e Dignidade das Pessoas com Deficiência (ONU).

$\mathrm{Na}$ legislação brasileira, alguns documentos podem ser referenciados, como a Constituição Federal de 1988 (BRASIL, 1988), que confere direito às pessoas com necessidades educacionais especiais (NEE) à educação, na rede regular de ensino; a Lei no. 10.098, de 19/12/2000 (BRASIL, 2000), que estabelece normas gerais e critérios para a promoção da acessibilidade nos espaços públicos e meios de transporte e comunicação; e o Parecer no. 17/2001 (BRASIL, 2001), que estabelece diretrizes para a educação especial na educação básica.

Existem discussões a respeito da forma correta que devem ser chamadas as pessoas que se encontram nessa situação. Conforme o Decreto no. 5.296, de 2/12/2004 (BRASIL, 2004), o termo deficiência significa uma restrição física, mental ou sensorial de natureza permanente ou transitória, que pode limitar a pessoa a exercer uma ou mais atividades essenciais da vida diária. A acessibilidade possibilita a inclusão social e para que a informação seja acessível é necessário romper barreiras. Sendo a biblioteca universitária a responsável por proporcionar a acessibilidade, ela precisa se adequar, tanto em relação ao espaço físico quanto à capacitação dos funcionários na prestação de serviços. Segundo Paula e Carvalho (2009, p. 71), "a escolha da melhor estrutura que proporcione o uso democrático dos espaços deve transpor ainda algumas dificuldades encontradas para o acesso à informação". 
Algumas bibliotecas são acessíveis e outras são apenas adaptadas; o ideal é que as bibliotecas possam oferecer uma boa acessibilidade e contar, também, com uma boa adaptação, conforme Gonzalez ${ }^{1}$ (2002 apud PAULA; CARVALHO, 2009, p. 72):

É importante fazer diferença entre biblioteca acessível e biblioteca adaptada. Biblioteca adaptada é aquela que segue as regras do desenho acessível, com rampas, banheiros adaptados, sinaleiras Braille, entre outras. A biblioteca acessível é a que disponibiliza a informação em qualquer suporte e provê acesso a todas as pessoas que dela necessitam, ou seja, segue os princípios do desenho universal.

Não só os espaços internos da biblioteca devem ser acessíveis e adaptáveis, mas, também, a estrutura do entorno da biblioteca, o que Pupo, Melo e Ferrés (2006) denominam de acessibilidade urbana. A acessibilidade urbana inclui o transporte público, a urbanização circundante da biblioteca e o número suficiente de vagas de estacionamento, com as seguintes características: sinalização horizontal e vertical com o símbolo internacional de acesso; localização mais próxima possível da entrada principal com o necessário rebaixamento de guia e sinalização tátil; e faixa adicional à vaga para circulação de cadeira de rodas (PUPO; MELO; FERRÉS, 2006).

A Associação Brasileira de Normas Técnicas (ABNT) disponibilizou a "NBR 9050 - Acessibilidade a Edificações, Mobiliário, Espaços e Equipamentos Urbanos"; bem como outras normas referentes aos direitos das pessoas com deficiência e destaca as seguintes definições (ABNT, 2004, p. 2):

a) acessibilidade: possibilidade e condição de alcance, percepção e entendimento para a utilização com segurança e autonomia de edificações, espaço, mobiliário, equipamento urbano e elementos;

b) acessível: espaço, edificação, mobiliário, equipamento urbano ou elemento que possa ser alcançado, acionado, utilizado e vivenciado por qualquer pessoa, inclusive aquelas com mobilidade reduzida. O termo acessível implica tanto acessibilidade física como de comunicação;

c) adaptável: espaço, edificação, mobiliário, equipamento urbano ou elemento cujas características possam ser alteradas para que se torne acessível; e

\footnotetext{
${ }^{1}$ GONZALEZ, C. J. Biblioteca acessível: serviço de informação para usuários com deficiência. 2002. Monografia (Departamento de Biblioteconomia e Documentação) - ECA, USP, 2002. Disponível em:

<http://www.scielo.br/scielo.php?pid=S0100-19652009000300005\&script=sci_arttext>. Acesso em: 2 Out. 2010.
} 
d) adaptado: espaço, edificação, mobiliário, equipamento urbano ou elemento cujas características originais foram alteradas posteriormente para serem acessíveis.

Tal norma (ABNT, 2004, p. 88), faz recomendações sobre a biblioteca, detalhando o que é necessário para que a mesma seja acessível e adaptada. A norma apresenta especificações sobre mobiliário, salas para estudo e leitura, distância entre as estantes e acervo, com fotos ilustrativas. Oferece, também, recomendações para serviços de autoatendimento, e traz algumas orientações específicas para deficientes visuais, que serão exploradas na próxima seção.

\subsection{Acessibilidade para pessoas com deficiência visual}

A biblioteca deve ter seus serviços voltados para um atendimento de excelência, prestando serviços e satisfazendo as necessidades de informação de diversos tipos de usuários. Os deficientes visuais devem ser incluídos nesse tipo de atendimento, tendo a garantia de satisfação ao procurarem a biblioteca. Além da acessibilidade e adaptação oferecidas pelas bibliotecas universitárias, é importante que haja uma preocupação, por parte dos profissionais da informação, em se capacitarem para atender bem esse público; possibilitando a melhor aprendizagem do estudante com cegueira ou com visão subnormal (baixa visão).

As pessoas com deficiências sentem-se discriminadas em algumas situações, por não conseguirem ter o acesso de forma mais independente às informações, no âmbito das bibliotecas. Conforme o Decreto nº. 3.956, de 8 de outubro de 2001, é promulgada a convenção interamericana para a eliminação de todas as formas de discriminação contra pessoas com deficiência. Tal documento afirma que as pessoas com deficiência possuem os mesmos direitos humanos e liberdades fundamentais que outras pessoas, inclusive o direito de não serem submetidas à discriminação por causa da deficiência.

Os sistemas educacionais estão sofrendo mudanças, eles estão cada vez mais inclusivos, com eliminação de barreiras, possibilitando o acesso ao conhecimento e oferecendo condições para que os estudantes tenham mais facilidade de acesso. Conforme colocado por Souza e Manoel (2008, p. 8):

Para pessoas com cegueira ou visão subnormal a efetivação do ato de leitura se dá no acesso às fontes de informação utilizando a escrita Braille, "livro falado" e os sistemas leitores de documentos eletrônicos desenvolvidos para as pessoas que têm acesso às tecnologias de comunicação e informação (TIC's).

As bibliotecas universitárias devem oferecer tratamento especial no momento de atender usuários com deficiência visual. Existem diversos tipos de 
deficiência física, a cegueira é uma delas. Segundo Tibola ${ }^{2}$ (apud FERNANDES; AGUIAR, s. d., p. 4):

Cegueira: é a perda total e/ou resíduos mínimos de visão, que leva o indivíduo a necessitar do "Sistema Braille" como meio de leitura e escrita, além de outros equipamentos específicos para o desenvolvimento educacional e integração social.

Visão subnormal: trata-se da pessoa que possui resíduo visual que a possibilita ler impressos a tinta, de forma ampliada, ou com o uso de equipamentos específicos.

Ao receber um deficiente visual na biblioteca, alguns cuidados devem ser tomados, evitando, assim, constrangimento e desconforto desnecessários, tanto para o usuário como para o atendente. Algumas pessoas possuem dúvidas de como se comportar diante de tais pessoas. Diante dessa realidade, a Organização Não-Governamental (ONG) Centro de Vida Independente (CVI)) 3 tem publicado, dentre outras ações, 0 manual de inclusão social, que faz recomendações de como se comportar diante de uma pessoa com deficiência visual.

Para a educação superior, os deficientes visuais contam com o apoio da Portaria no. 3.284, de novembro de 2003, que exige alguns requisitos de acessibilidade, contribuindo, assim, para o seu bom rendimento na universidade. A biblioteca universitária também é responsável por essa acessibilidade. A Secretaria de Educação Superior, com apoio da Secretaria de Educação Especial, estabelece requisitos de acessibilidade, tomando-se como referência a NBR 9050 da ABNT (ABNT, 2004). No que concerne aos estudantes com deficiência visual, o compromisso da instituição se estende do início à conclusão do curso superior, no seguinte âmbito:

a) manter sala de apoio equipada com máquina de datilografia Braille, impressora Braille acoplada ao computador, sistema de síntese de voz, gravador e fotocopiadora que ampliem textos, software de ampliação de tela, equipamento para ampliação de textos para atendimento ao estudante com visão subnormal, lupas, réguas de leitura, scanner acoplado a computador; e

b) adotar um plano de aquisição gradual de acervo bibliográfico em Braille e de fitas sonoras para uso didático.

A tecnologia possui grande relevância para os deficientes visuais, pois, através dela, o acesso à informação torna-se mais fácil, ou seja, mais acessível. Alguns equipamentos e softwares são necessários para

\footnotetext{
${ }^{2}$ TIBOLA, I. M. (Org.). Pessoa portadora de deficiência: integrar é o primeiro passo. Curitiba: SEED, 1998.

${ }^{3}$ Localizada em Maringá, no Paraná. Disponível em: <http://www.cvi-maringa.org.br/index.php>. Acesso em: 10 out. 2010.
} 
que o deficiente visual possa ter acesso de modo eficaz às informações. Os recursos óticos ajudam a melhorar o desempenho visual através da ampliação de imagem, como óculos, lupas e telescópios. As universidades e as bibliotecas universitárias podem disponibilizá-los, conforme demonstrado por Ferreira (2008).

\section{Metodologia}

\subsection{Biblioteca Braille José Álvarez de Azevedo}

Conforme colocado anteriormente, o objetivo do trabalho é demonstrar que bibliotecas universitárias podem ser acessíveis aos deficientes visuais, sem grandes custos para a instituição mantenedora. Nesse sentido, elas podem se preparar para receber os usuários, mesmo que ainda não possuam estudantes com deficiência visual matriculados. As sugestões, aqui apresentadas, fundamentam-se na literatura da área e na pesquisa de campo realizada na Biblioteca Braille José Álvarez de Azevedo, localizada na cidade de Goiânia, estado de Goiás. A biblioteca disponibiliza um acervo de 2.500 itens informacionais, incluindo livros impressos, acervo em áudio e periódicos em Braille. Possui uma equipe de sete funcionários, sendo uma bibliotecária ${ }^{4}$, dois auxiliares, um monitor de informática e três digitalizadores. Todo o trabalho é feito por pessoas com visão subnormal ou cegos, apenas uma funcionária possui visão normal ${ }^{5}$.

No ambiente da biblioteca, há espaço para sala de leitura com cabines individuais para adultos e crianças. Torna-se necessário que a equipe seja bem preparada para operar os equipamentos, que são trabalhosos e, também, por lidar com muitos usuários que, embora sejam deficientes visuais, não foram alfabetizados no sistema Braille e, portanto, não possuem domínio do mesmo. Dessa forma, os livros em áudio são uma forma muito recorrente de disseminação das informações. Muitos livros são preparados pelos próprios funcionários, que os digitalizam e os transformam em áudio.

Na Biblioteca Braille, os livros impressos em Braille não possuem muita demanda, a procura maior é pelo acervo em áudio, que contempla assuntos relativos a concursos públicos e textos acadêmicos/científicos. A biblioteca é muito procurada por usuários que estão estudando para concursos públicose as pastas de concurso constituem um produto de informação importante para atender a essa demanda. A bibliotecária possui um acervo catalogado no computador por assunto. Dessa forma, quando um usuário chega com uma demanda de informação, ela vai às pastas para procurar pelo assunto específico. Realiza, também, pesquisas na internet, através do programa sintetizador de voz denominado Jaws e pesquisas são encomendadas e respondidas por e-mail gratuitamente.

Outro serviço bastante dinâmico na biblioteca é a produção dos livros digitais. Funciona da seguinte forma: o usuário traz uma obra

\footnotetext{
${ }^{4}$ Com apenas $5 \%$ da capacidade de visão.

${ }^{5}$ À época da pesquisa de campo, em outubro de 2010.
} 
impressa à biblioteca e a mesma faz a conversão daquela obra para o formato digital. O livro é escaneado através do programa OpenBook e é salvo em formato Word. Em seguida, faz-se a correção das imperfeições do escaneamento, um trabalho detalhista e demorado. Como esse trabalho também é feito por funcionários de visão subnormal, utiliza-se o Zoom Text, que é um programa para aumentar a tela. Interessante observar que os programas sintetizadores de voz, tanto Jaws quanto Doxvox, não fazem a leitura da imagem do texto. Dessa forma, um texto com imagens pode ser trabalhado de duas formas: ou é feita uma descrição da imagem e o programa lê a descrição ou simplesmente pulase aquela imagem, como se ela não existisse no texto. Depois que o material fica pronto, o usuário pode salvá-lo no pen drive e ouvi-lo fora do recinto da biblioteca.

A composição do acervo da biblioteca se dá, então, pela produção dos livros em áudio digitalizados, através da participação em listas de trocas de livros e através de doações da Fundação Dorina Nowill Para Cegos6, em São Paulo e do Instituto Benjamin Constant7, no Rio de Janeiro. A Fundação Dorina Nowill Para Cegos produz livros em Braille, falados e no formato digital acessível, que são distribuídos gratuitamente para pessoas com deficiência visual e para centenas de escolas, bibliotecas e organizações de todo o Brasil. O contato é feito por telefone e é necessário o preenchimento de formulário. O Departamento Técnico Especializado (DTE) do Instituto Benjamin Constant planeja, coordena, orienta e supervisiona a execução de atividades técnicas nas áreas de pesquisa, produção e distribuição de documentos e material especializado para as ações acadêmicas e atividades cotidianas. Atua na produção, no registro e na divulgação do conhecimento construído nas questões relativas às pessoas com deficiência visual, além de transcrever, imprimir e distribuir material impresso no sistema Braille.

Conforme a bibliotecária, não é interessante ter atualmente acervo impresso em Braille na biblioteca, com exceção dos livros de literatura. Os principais motivos são o trabalho empreendido, inclusive equipamentos adequados e profissionais preparados para utilizá-los, bem como o volume enorme que ocupam nas estantes. O acervo da biblioteca é composto também de CDs, que exigem um preparo técnico da bibliotecária antes de irem para as estantes. Existe, também, o usuário que não foi alfabetizado em Braille, como ocorre com pessoas que ficaram cegas depois de adultas, por uma fatalidade qualquer. Muitas vezes, essas pessoas utilizam as salas de leitura, nas quais um funcionário faz a leitura dos conteúdos para os usuários.

A visita à Biblioteca Braille foi fundamental para conhecer toda sua dinâmica de serviços e funcionamento, além de contribuir para etapas importantes do desenvolvimento do trabalho, por meio de experiência vivenciada pela bibliotecária e funcionários da biblioteca.

6 Disponível em: <http://www.fundacaodorina.org.br/FDNC/Quem_Somos.html>. Acesso em: 01 nov. 2010.

Disponível em: <http://www.ibc.gov.br/>. Acesso em: 1 nov. 2010. 


\subsection{Softwares e equipamentos para bibliotecas universitárias}

A biblioteca pode se utilizar dos benefícios dos softwares, os quais permitem que os deficientes visuais possam usufruir da tecnologia para se tornarem mais interativos e independentes quando buscam por informações e conhecimento. Os leitores de tela são programas que interagem com o sistema operacional do computador, capturam as informações textuais e as transformam em resposta falada, através do uso do sintetizador de voz. O usuário pode ouvir o que está sendo demonstrado à medida que navega pelo sistema e executa comandos. Pupo, Melo e Ferrés (2006) apresentam os seguintes softwares:

1) DOSVOX - sistema operacional que se comunica com o usuário através de síntese de voz, em português, o qual foi produzido pelo Núcleo de Computação Eletrônica da UFRJ e possui distribuição gratuita. 0 sistema roda em Windows 95 ou superior e permite um alto grau de independência do deficiente visual. O que diferencia o DOSVOX de outros sistemas é que a comunicação homem-máquina é mais simples e estabelece um diálogo amigável, através de programas específicos e interfaces adaptativas. Oferece ambiente de trabalho com jogos adultos e infantis, editor de textos, calculadora, navegador para internet, lente de aumento para pessoa com visão subnormal. Permite que se imprima em Braille, caso haja uma impressora Braille acoplada ao computador. Pode ser baixado gratuitamente no site do Núcleo de Computação Eletrônica8;

2) Delta Talk - programa nacional que permite a interação com o computador de maneira natural. O programa fala adequadamente e existe a opção de escolha de três vozes diferentes. Números, datas, horas e abreviações são lidos com entonação determinada automaticamente, através de análise linguísticas do texto ${ }^{9}$;

3) Virtual Vision - software pago e desenvolvido em 1997 pela empresa Micropower, dos Estados Unidos. O Virtual Vision lê para o usuário todo conteúdo da tela selecionado por meio do teclado, inclusive planilhas, tabelas e sites na Internet. Roda em ambiente Windows e é capaz de interagir com diversos programas como os do pacote Office, Internet Explorer, MSN, Skype, dentre outros;

4) Jaws - software pago e considerado um dos leitores de tela mais populares e mais completos do mundo, produzido pela empresa norteamericana Freedom Scientific, roda em português e possui um software de sintetizador de voz que utiliza a própria placa de som do computador;

5) Openbook - converte o texto escaneado em texto eletrônico para ser lido pelo sintetizador de voz ou convertido em MP3. As pessoas com visão subnormal podem escolher entre a exibição visual por ampliação, espaçamento especial entre caracteres e ajuste de cores de alto contraste, é um OCR (Optical Character), uma tecnologia para reconhecimento óptico dos caracteres. A versão mais atual é a OpenBook 9.0; e

\footnotetext{
${ }^{8}$ Disponível em: <http://intervox.nce.ufrj.br/>. Acesso em: 10 out. 2010.

${ }^{9}$ Produzido pela MicroPower. Disponível em: <http://www.micropower.com.br/v3/pt/index.asp>. Acesso em: 10 out. 2010.
} 
6) Magic - é um programa que traz as funções de síntese de voz e ampliação simultaneamente. Próprio para usuários com visão subnormal. Pode ser ajustado de acordo com as necessidades do usuário e aumenta de 2 a 16 vezes a informação selecionada ou Braille.

Pupo, Melo e Ferrés (2006) sugerem, ainda, equipamentos e instrumentos auxiliares para maior conforto e comodidade do deficiente visual no processo de leitura e escrita, tais como: monitor de 17" tela plana, suporte para elevação do monitor, suporte para apoio de textos complementares, teclado e filtro de proteção (raios catódicos). Os raios catódicos podem auxiliar na escrita e na leitura, diminuindo a luminosidade. $E$, também, os recursos não ópticos que auxiliam no processo, sugeridos por Pupo, Melo e Ferrés (2006): controle da iluminação do ambiente; transmissão da luz com o auxílio de lentes absortivas; controle da reflexão através de tiposcópio, visores, oclusores laterais e lentes polarizadas; uso de acessórios como caneta de ponta porosa preta, lápis de escrever $6 \mathrm{~B}$, dentre outros; ampliação através do Sistema de Circuito Fechado de Televisão (CCTV) ou da lupa eletrônica e apoio para leitura, mediante prancheta com aproximação para suporte da folha de leitura.

\section{Conclusões}

Um projeto de tal envergadura na biblioteca universitária exige o trabalho de uma equipe multidisciplinar e deve prever, minimamente: a) conhecimento da instituição na qual a biblioteca se insere; b) ajustes à missão, objetivos e metas institucionais; c) conhecimento do planejamento estratégico institucional; d) envolvimento das pessoas diretamente interessadas; e) noções e fundamentos de desenho universal; f) embasamento legal para as justificativas; g) consulta aos portais da temática referencial; h) respaldo de consultas a órgãos governamentais pertinentes; e i) consultas técnicas e entrevistas a outros profissionais que tenham desenvolvido boas práticas (PUPO; MELO; FERRÉS, 2006).

Com a disponibilização de computadores conectados à Internet e o uso do DOSVOX, o deficiente visual consegue acessar as informações da Internet, e todos os serviços disponíveis na rede mundial de computadores. Considerando tal dimensão de benefícios, o deficiente poderá acessar um universo muito grande de informações para atender aos mais diversos interesses.

Boa parte do acervo impresso, em CDs e DVDs pode ser adquirida por doações da Fundação Dorina Nowill para Cegos e do Instituto Benjamin Constant. Tal instituto transcreve, imprime e distribui gratuitamente material impresso no Sistema Braille para todo o país. 0 Instituto Benjamin Constant oferece também cursos de curta duração na área da deficiência visual, qualificação de professores e envio de técnicos para oferta de cursos em universidades, secretarias de educação e instituições do país, e proporciona estágio a acadêmicos e profissionais envolvidos com a temática.

Outro recurso importante para as bibliotecas universitárias é a produção dos livros digitais, ou seja, a conversão dos livros impressos 
para o formato digital. Já os livros falados possuem um custo menor de produção e ocupam menos espaço nas prateleiras. Os livros digitais e falados permitem maior interação dos usuários com 0 material, contribuindo para as diversas formas de leitura. Conforme indica Rosa (s.d.), o livro digital permite a utilização de uma série de ferramentas, como texto escrito e centralizado, acompanhamento do audiolivro, ampliação da fonte, busca por palavras-chave e 0 acesso à página almejada. Nesse contexto, foi lançado pelo governo federal em 2009, o programa MecDaisy, que possibilita a geração de livros digitais falados, com facilidade de navegação pelo texto, anexo de anotações e exportação do texto para impressão em Braille, dentre outros recursos. O software pode ser baixado gratuitamente na internet, e o programa pode ser rodado em Windows ou Linux10.

O acesso aos recursos disponíveis para os deficientes visuais sugere que os mesmos tendem a se tornarem cada vez mais independentes em relação à busca por informação, desde que tenham acesso aos instrumentos adequados. Uma condição básica para o acesso à tecnologia é que o deficiente visual tenha o curso de informática e domine bem o teclado do computador, já que o mouse não é utilizado. Esse não tem sido um problema para o deficiente visual goiano, que pode contar com os cursos oferecidos gratuitamente pelo Centro Brasileiro de Reabilitação e Apoio ao Deficiente Visual (CEBRAV).

Tão importante quanto o uso de equipamentos e softwares é o preparo dos profissionais para o atendimento aos usuários com deficiência visual, conforme colocado no início deste trabalho. A universidade deve ser uma instituição acessível em diversos aspectos: na arquitetura, na comunicação, na atitude das pessoas e no acesso à informação e ao conhecimento. Ela deve apoiar os estudantes do início ao final do curso, garantindo que eles concluam o mesmo. A biblioteca pode contribuir para formação de leitores e pesquisadores mais independentes, garantindo aos deficientes visuais o direito de serem participantes ativos no processo de construção e difusão do conhecimento e da cultura.

A educação superior possui papel fundamental na preparação de seus estudantes para que se tornem profissionais capacitados no futuro. Por ter como uma de suas responsabilidades apoiar os estudantes na conclusão do curso, fornecendo informações confiáveis de modo acessível, a biblioteca universitária deve garantir que as pessoas que a procuram tenham o ambiente propício para o bom desenvolvimento de suas pesquisas e trabalhos. Não apenas os estudantes, mas, também, professores, servidores técnico-administrativos e qualquer membro da comunidade acadêmica com deficiência visual que necessite de acesso à informação e ao conhecimento.

As bibliotecas universitárias devem procurar adequar suas unidades para que possam atender toda diversidade de usuários que procuram por informações e os bibliotecários/profissionais da informação possuem parte nessa responsabilidade. As unidades de informação têm como uma de

${ }^{10}$ Disponível em: <http://www.intervox.nce.ufrj.br/mecdaisy/index.htm>. Acesso em: 2 jan. 2011. 
suas funções primordiais conhecerem a organização em que se situam, para que possam subsidiar o planejamento tanto na fase em que o plano, programa ou projeto são elaborados, como também no momento em que as ações serão implementadas. Através desse conhecimento ela irá colocar em prática suas ações, planos e projetos para beneficiarem o maior número de pessoas, oferecendo produtos e serviços que atendam às expectativas de seus usuários. O rompimento das barreiras em torno da acessibilidade é essencial para permitir que essas pessoas sejam incluídas na sociedade da informação, pois não se deve pensar apenas nas mudanças física da biblioteca.

É preciso ir além: desenvolver uma conscientização por parte das pessoas que trabalham nas unidades de informação, uma forma de pensar mais inclusiva, deixando isso refletir em suas atitudes. Na educação superior, os deficientes visuais contam com o apoio da Portaria no. 3.284, de novembro de 2003, que exige alguns requisitos de acessibilidade, contribuindo assim para o seu bom rendimento na universidade. De acordo com todas as etapas seguidas neste trabalho, foram sugeridos equipamentos e softwares direcionados para acessibilidade de deficientes visuais em bibliotecas universitárias, e alguns deles se encontram disponíveis gratuitamente através da internet.

\section{Referências}

ASSOCIAÇÃO BRASILEIRA DE NORMAS TÉCNICAS. NBR 9050: Acessibilidade a edificações, mobiliário, espaços e equipamentos urbanos. 2. ed. Rio de Janeiro, 2004. Disponível em: <http://www.mpdft.gov.br/sicorde/NBR9050-31052004.pdf>. Acesso em: 24 set. 2010.

BRASIL. Lei no 10.048, de 08 de novembro de 2000. Dá prioridade de atendimento às pessoas que especifica, e dá outras providências. Diário Oficial da União, 9 nov. 2000 Disponível em: <http://www.planalto.gov.br/ccivil_03/Leis/L10048.htm>. Acesso em: 9 out. 2010.

BRASIL. Ministério da Educação. Conselho Nacional de Educação. Parecer CNE/CEB 17/2001. Diretrizes Nacionais para a Educação Especial na Educação Básica. Diário Oficial da União, Seção 1, p. 46, 17 ago. 2001. Disponível em: <http://portal.mec.gov.br/cne/arquivos/pdf/CEB017 2001.pdf>. Acesso em: 9 out. 2010.

BRASIL. Portaria no 3.284, de 07 de novembro de 2003. Dispõe sobre requisitos de acessibilidade de pessoas portadoras de deficiências, para instruir os processos de autorização e de reconhecimento de cursos, e de credenciamento de instituições. Diário Oficial da União, n. 219, seção 1, p. 12, 11 nov. 2003. Disponível em: <http://portal.mec.gov.br/seesp/arquivos/pdf/port3284.pdf>. Acesso em: 9 out. 2010. 
BRASIL. Presidência da República. Casa Civil. Subchefia para Assuntos Jurídicos. Constituição da República Federativa do Brasil.1988. Disponível em: <http://www.planalto.gov.br/ccivil 03/Constituicao/Constitui\%C3\%A7ao.htm>. Acesso em: 9 out. 2010.

BRASIL. Presidência da República. Casa Civil. Subchefia para Assuntos Jurídicos. Decreto no 3.956 de 8 de outubro de 2001. Diário Oficial da União, 9 out. $2001 . \quad$ Disponível em: <http://www6.senado.gov.br/legislacao/ListaTextoIntegral.action?id= 221026\&norma=233683 > . Acesso em: 9 out. 2010.

BRASIL. Presidência da República. Casa Civil. Subchefia para Assuntos Jurídicos. Decreto no 5.296 de 2 de dezembro de 2004. Diário Oficial da União, 3 dez. 2004. Disponível em:< http://www.planalto.gov.br/ccivil 03/ ato2004-2006/2004/decreto/d5296.htm >.

Acesso em: 9 out. 2010.

CONVENÇÃO DA ORGANIZAÇÃO DOS ESTADOS AMERICANOS. Decreto 3956 promulga a Convenção Interamericana para Eliminação de Todas as Formas de Discriminação Contra as Pessoas Portadoras de Deficiência. Disponível em: <http://portal.mec.gov.br/arquivos/pdf/decreto3956.pdf>. Acesso em: 09 out. 2010.

FERNANDES, D. M. S.; AGUIAR, I. M. de. O deficiente visual e a biblioteca central da UEL: relato de experiência. Londrina: [s. n.], [s. d.]. Disponível em: <snbu.bvs.br/snbu2000/docs/pt/doc/t061.doc>. Acesso em: 9 out. 2010.

FERREIRA, A. F. B. C. Biblioteca Louis Braille do Instituto Benjamin Constant: assegurando ao deficiente visual acesso ao conhecimento. Revista ACB: Biblioteconomia em Santa Catarina, Florianópolis, v. 13, n. 1 , p. 282-290, jan./jun., 2008. Disponível em: <http://revista.acbsc.org.br/index.php/racb/article/viewArticle/554>.

Acesso em: 9 out. 2010.

MAZZONI, A. A. et al. Aspectos que interferem na construção da acessibilidade em bibliotecas universitárias. Ciência da Informação, Brasília, v. 30, n. 2, p. 29-34, maio/ago. 2001. Disponível em: <http://www.scielo.br/pdf/ci/v30n2/6209.pdf/>. Acesso em: 24 set. 2010.

PAULA, S. N. de; CARVALHO, J. O. F. de. Acessibilidade à informação: proposta de uma disciplina para cursos de graduação na área de biblioteconomia. Ciência da Informação, Brasília, v. 38, n. 3, p. 64-79, set./dez. 2009. Disponível em: <http://revista.ibict.br/index.php/ciinf/article/viewArticle/1640/>. Acesso em: 24 set. 2010.

PUPO, D. T. (Org.); MELO, A. M. (Org.); FERRÉS, S. P. (Org.). Acessibilidade: discurso e prática no cotidiano das bibliotecas. Campinas: Unicamp, 2006. 
ROSA, S. Fundação Dorina: do Braille ao livro digital. [s. d.]. Disponível em:

$<$ http://edutec.unesp.br/index.php?option=com_content\&view=article\&id $=252$ : fundacao-dorina-do-braille-ao-livrodigital\&catid=1: portal\&Itemid=125>. Acesso em: 2 Jan. 2011.

SOUZA, S. C. de; MANOEL, V. de A. Praticando acessibilidade comunicacional: cooperação entre biblioteca universitária e programa de promoção de acessibilidade. Revista ACB: Biblioteconomia em Santa Catarina, Florianópolis, v. 13, n. 1, p. 7-17, jan./jun. 2008. 